\title{
Extent Reflecting Overall Dietary Amino Acids Composition Adherence to the Human Requirement Amino Acids Pattern is Associated with the Development of type 2 Diabetes
}

\author{
Wei Duan \\ Harbin Medical University \\ Tianshu Han \\ Harbin Medical University \\ Yanhe Zhao \\ Harbin Medical University \\ Huanyu Wu \\ Harbin Medical University \\ Hu Sun \\ Harbin Medical University \\ Zhen Tian \\ Harbin Medical University \\ Jiemei Wang \\ Harbin Medical University \\ Ruiqi Shan \\ Peking University Health Science Centre \\ Liyan Liu \\ Harbin Medical University \\ Yuntao Zhang \\ Harbin Medical University \\ Ying Li \\ Harbin Medical University \\ C Sun ( $\nabla$ changhaosun2002@163.com ) \\ Harbin Medical University
}

Original investigation

Keywords: Amino acids, compositions, quality index, type 2 diabetes mellitus

Posted Date: July 24th, 2020 
DOI: https://doi.org/10.21203/rs.3.rs-42386/v1

License: (c) (i) This work is licensed under a Creative Commons Attribution 4.0 International License. Read Full License 


\section{Abstract}

Background: This study aimed to elucidate whether dietary amino acids (AAs) composition is associated with type 2 diabetes mellitus (T2DM), and to investigate whether and how serum AAs profiles mediated this association.

Methods: Two prospective cohorts of 1750 and 4024 adults aged 20-74 year-old were enrolled with mean values of 4.2 and 5.3 years follow-up. Dietary AAs compositions index (AACl) was developed to reflect the overall quality of dietary AAs composition with the lower the $\mathrm{AACl}$ value, the higher quality of dietary AAs compositions. Multivariate linear regression and logistic regression models were used to examine associations of AACI with serum AAs profiles and incidence of T2DM.

Results: The AACl was associated with the incidence of T2DM with the relative risk and $95 \% \mathrm{Cl}$ from the bottom to the top tertiles being 1.00, 1.39 (0.85-2.26) and 1.68 (1.01-2.91), and 1.00, 1.30 (0.98-1.34) and 1.63 (1.19-2.23) in the two cohorts, respectively. The AACI was positively associated with serum valine, isoleucine, glutamic acid and phenylalanine, and it was negatively associated with serum glycine and histidine in both cohorts $(P<0.01)$. Among these serum AAs, valine, glutamic acid and histidine consistently and partially mediated the association between the AACl and incidence of T2DM in the two cohorts, with total mediation effects of $33.4 \%$ and $54.6 \%$, respectively.

Conclusion: Dietary AAs composition was associated with the incidence of T2DM through influencing its serum profiles. Future dietary strategies for prevention and treatment of T2DM should focus on improvement of overall quality of dietary AAs compositions.

\section{Background}

Amino acids (AAs) have been increasingly studied as playing roles in development of insulin resistance and type 2 diabetes mellitus (T2DM) $(1,2)$. However, current studies regarding relationship between dietary AAs and T2DM have been frequently inconsistent (3-7), and it is still largely unknown whether and how serum AAs mediated the relationship between dietary AAs and T2DM.

Previous studies commonly focused on relationships between individual dietary AA and T2DM (3-7), but ignoring that different dietary AAs compositions in overall diet may influence biological value of protein intake, resulting in different absorbed-, utilized- and metabolic-rates of AAs (8-11), which may contribute to these inconsistent results. Further, the varied absorbed-, utilized- and metabolic-rates of AAs in different dietary AAs composition also make it difficult to capture link between individual dietary AA and its plasma levels. Therefore, intake of a single kind of AA may not be commonly reflected in its serum AA level, making it remain controversial whether relationship between dietary AAs and T2DM was mediated by serum AAs $(3,12-14)$. These key questions probably hindered for shaping useful dietary guidelines of AAs in prevention and management of T2DM. For example, although numerous studies have reported associations between high plasma branched chain AAs (BCAAs) and increased risk of T2DM (15-19), it is still largely unknown whether dietary BCAAs intake should be constrained in prevention and management 
of T2DM because previous studies indicated that plasma BCAAs levels are not direct reflection of dietary BCAA intakes $(3,12-14)$, and contradictory results have been reported in previous studies regarding dietary BCAAs intake and risk of T2DM $(3,4,14,20,21)$.

The concept of human requirement amino acids pattern (HRAAP) may provide clues for solving these questions. It provided and emphasized the necessity of a suitable composition of dietary essential AAs to achieve optimal absorbed-, utilized- and metabolic-rates of AAs, which has been proved to be successful in maintaining normal function of tissues and organs in body (22). However, there is still no study have assessed whether this concept could be applied in the field of T2DM. Based on this concept, we hypothesized that in order to prevent T2DM, overall dietary AAs composition should be adherence to the HRAAP. The closer adherence to the HRAAP, the higher absorbed-, utilized- and metabolic-rates of AAs in body were, which thereby maintained plasma AAs profiles in appropriate levels. Otherwise, the absorbed-, utilized- and metabolic-rates of AAs will be influenced, showing disordered plasma AAs profiles, and some dysregulated AAs may result in insulin resistance and subsequent T2DM.

To validate our hypothesis, we intended to develop a dietary AAs compositions index (AACI) to reflect the extent to which overall dietary AAs compositions adherence to the HRAAP, and examined association between the $\mathrm{AACl}$ and future risk of T2DM in two prospective cohorts. Once the association between the $\mathrm{AACl}$ and T2DM was confirmed, we intended to further clarify whether the association between the AACl and T2DM was mediated by serum AAs for providing complete evidence in this issue.

\section{Methods}

\section{Study Population}

Two prospective study cohorts were recruited in Harbin, China, to investigate the impact of diet and nutrition on Chronic Non-communicable Disease. They were the Harbin People Health Study (HPHS) and the Harbin Cohort Study on Diet, Nutrition and Chronic Noncommunicable Disease (HDNNCDS) (registered at www.chictr.org as ChiCTR-ECH-12002721). Participants in the HPHS and HDNNCDS were recruited in 2008 and 2010, and the first in-person follow-up survey was completed in 2012 and 2016, with mean of 4.2 and 5.3 years follow-up. Detail information of the two cohorts was described elsewhere $(23,24)$. Briefly, a total of 1750 participants in the HPHS and 4024 participants in the HDNNCDS aged 20-74 years old who finished the baseline survey, measured fasting serum profiles of amino acids, were free of diabetes and had calorie intake ranging from $500-4500 \mathrm{kcal} /$ day at baseline were included in this study.

The two cohort studies were approved by the ethics committee of Harbin Medical University. The investigations were conducted in accordance with the Declaration of Helsinki, and written informed consent was provided by all participants. The methods in this study were in accordance with the approved guidelines.

\section{Questionnaire survey}


Detailed in-person interviews were administered by trained personnel using a structured questionnaire to collect information on demographic characteristics, lifestyles, physical condition and anthropometric characteristics in the two cohorts. Current smokers were defined as those who smoked at least 100 cigarettes in a lifetime or smoked every day or currently smoked some days. Current drinkers were defined as those who consumed $\geq 1$ alcoholic drink each month in the 12 months prior to the survey. Regular exercise was defined as any kind of recreational or sport physical activity other than walking for work or life performed at least 30 minutes for three or more days per week. Family history of diabetes was defined as diabetes in first- or second-degree relatives.

\section{Dietary information}

Dietary habits were recorded through food frequency questionnaire (FFQ). Before dietary surveys, two random subgroups of residents were recruited and were asked to complete two FFQs (FFQ1 and FFQ2) and a 3-day dietary record (DR) to validate the reliability of the FFQ. There was satisfactory consistency between two FFQs and the DR, indicating the FFQ is reliable method for assessing dietary intakes (24). The FFQ covered 103 food items assigned into 14 food groups: rice, wheaten foods, potato and its products, beans and its products, vegetables, fruits, livestock and its products, poultry and its products, dairy and its products, eggs and its products, fish and its products, snacks, beverage, and ice cream. The frequency and amount of each food item were recorded to calculate foods and nutrients intakes. According the nutrient contents in the Chinese Food Composition Table (25), the nine essential dietary amino acids and two conditionally essential amino acids including isoleucine, leucine, lysine, methionine, phenylalanine, threonine, tryptophan, valine, histidine, cysteine and tyrosine were calculated by summing the amounts from each food item. The Alternate Healthy Eating Index was calculated and used to assess the overall diet quality (26).

\section{Development of AACI}

The AACI was developed mainly based on the HRAAP reported by World Health Organization in 2007(22). The AACl was developed in two steps. First, the ratio between eleven amino acids including isoleucine, leucine, lysine, methionine, phenylalanine, threonine, valine, histidine, tryptophan, cysteine and tyrosine were calculated for deriving the composition of each AAs in the HRAAP $\left(\beta_{\text {ratio }} s\right)$.

Similarly, the ratio between eleven dietary amino acids intakes and dietary tryptophan intake were calculated for deriving the actual composition of these AAs in diet. The satisfaction levels of the composition of each AAs adherence to the HRAAP were calculated based on the following equation:

Second, the sum of satisfaction levels of each AAs were calculated for the $A A C l$, indicating the extent that overall dietary amino acids composition adherence to the HRAAP. The lower the AACl, the more adherence 


\section{Anthropometric measurements and Biochemical analyses}

Anthropometric measurements, including height, weight, and waist circumference, were obtained by welltrained examiners, with the participants wearing light, thin clothing and no shoes. Body weight and height were measured to the nearest $0.1 \mathrm{~kg}$ and $0.1 \mathrm{~cm}$, respectively. Body mass index (BMI) was calculated as weight $(\mathrm{kg})$ divided by the square of the height in meters $\left(\mathrm{m}^{2}\right)$. An oral glucose tolerance test was performed in the two cohorts, according to the World Health Organization guidelines, for each subject. Serum glucose, triglyceride (TG), total cholesterol (TC), high-density lipoprotein cholesterol (HDL-c) and low-density lipoprotein cholesterol (LDL-c) were determined by an automatic analyzer (Hitachi 7100, Tokyo, Japan). Serum insulin was measured by Chemiluminescence Immune Analyzer. Glycosylated hemoglobin (HbA1c) was determined by high performance liquid chromatography (BIO-RAD VARIANT 2, USA). Homeostasis assessment model for IR were used to estimate hepatic IR (HOMA2-IR) with HOMA2 calculator updated by the University of Oxford in 2004, which is available from https://www.dtu.ox.ac.uk/homacalculator/.

\section{Serum amino acids measurement}

Serum preparation for AAs quantitation was carried out as previously described (27). Targeted analysis of serum amino acids profiles was performed by a Waters ACQUITY Ultra performance liquid chromatography (UPLC) system (Waters Corporation, Milford, MA) coupled to a Waters Xevo TQD mass spectrometer (MS) (Waters Corporation, Manchester, U.K.). The methods of UPLC and MS were described and validated in previous study. Eighteen AAs, including threonine, glutamine, arginine, valine, leucine, isoleucine, phenylalanine, tryptophan, serine, methionine, glycine, proline, histidine, alanine, lysine, glutamic acid, aspartic acid tyrosine, were determined in this study.

\section{Outcome measures}

Type 2 diabetes was identified by self-reports of a history of diabetes diagnosis, and/or fasting blood glucose $\geq 7.0 \mathrm{mmol} / \mathrm{L}$, and/or 2-h glucose $\geq 11.1 \mathrm{mmol} / \mathrm{L}$, and/or receiving treatment for diabetes. Incident type 2 diabetes cases were 385 in the HDNNCDS and 185 in the HPHS.

\section{Statistical analysis}

All statistical analyses were performed in the R version 3.0.3 (http://www.r-project.org/), and all P-values were two tailed and $p<0.05$ was considered statistically significant. Baseline characteristics are presented as mean (SD) for continuous variables and percentages for categorical variables. For AACl and single intake of dietary AAs, the cutoff points were calculated. The AACl were categorized by tertiles, and the lowest tertile was used as the reference category. Baseline characteristics were compared using one-way ANOVA for continuous variables and the chi-square test for categorical variables across tertiles of the 
$\mathrm{AACl}$. Logistic regression models were performed to examine association between the tertiles of $\mathrm{AACl}$ and incidence of T2DM. Linear regression was used to explore the association between the $\mathrm{AACl}$ and profiles of serum AAs levels. Once the association between the AACl and serum AAs levels had been confirmed, mediation models were constructed to examine whether and how the association of the AACl with future risk of T2DM was mediated by serum AAs using R package Lavaan (28).

\section{Results}

\section{Baseline characteristics of participants in the two cohorts}

Participants in the HDNNCDS were older, and had higher alcohol consumption rate, calorie intake, protein intake and saturated fat intake than those in the HPHS. Fasting glucose, TC, TG and LDL-C were significantly higher in the HDNNCDS than those in the HPHS (Supplementary Table 1) [see Additional file 1]. The mean levels of study variables according to tertiles of AACl were presented in the Table 1 . In the HDNNCDS, as the AACI at baseline increased from the bottom to the top tertile, proportion of men, smoking rate, alcohol rate, BMI, gradually increased and protein intake, Fiber intake saturated fatty acid intake, TC levels and HDL-C levels gradually decreased. In the HPHS, BMI gradually increased, and protein intake, saturated fatty acid intake and HDL-C gradually decreased ( $P<0.05$ for all cases). 
Table 1

Baseline characteristics of participants by tertiles of AACI in the HPHS and HDNNCDS

\begin{tabular}{|c|c|c|c|c|c|c|c|c|}
\hline & HPHS & & & & HDNNCDS & & & \\
\hline & $\begin{array}{l}\text { Tertile } \\
1 \\
(\mathrm{~N}= \\
584)\end{array}$ & $\begin{array}{l}\text { Tertile } 2 \\
(\mathrm{~N}=582)\end{array}$ & $\begin{array}{l}\text { Tertile } \\
3 \\
(\mathrm{~N}= \\
584)\end{array}$ & $\begin{array}{l}P- \\
\text { value }\end{array}$ & $\begin{array}{l}\text { Tertile } 1 \\
(\mathrm{~N}=1341)\end{array}$ & $\begin{array}{l}\text { Tertile } 2 \\
(\mathrm{~N}= \\
1341)\end{array}$ & $\begin{array}{l}\text { Tertile } 3 \\
(\mathrm{~N}= \\
1342)\end{array}$ & $\begin{array}{l}P \text { - } \\
\text { value }\end{array}$ \\
\hline $\begin{array}{l}\text { Age } \\
\text { (years) }\end{array}$ & $\begin{array}{l}44.9 \\
(10.7)\end{array}$ & $\begin{array}{l}46.5 \\
(10.3)\end{array}$ & $\begin{array}{l}46.4 \\
(10.3)\end{array}$ & 0.017 & $48.7(9.7)$ & $49.6(9.4)$ & $50.3(9.6)$ & $\begin{array}{l}< \\
0.001\end{array}$ \\
\hline $\begin{array}{l}\text { Men }[\mathrm{n} \\
(\%)]\end{array}$ & $\begin{array}{l}149 \\
(25.7)\end{array}$ & $194(33.3)$ & $\begin{array}{l}194 \\
(33.3)\end{array}$ & 0.005 & $362(27.0)$ & $454(33.9)$ & $524(39.0)$ & $\begin{array}{l}< \\
0.001\end{array}$ \\
\hline $\begin{array}{l}\text { BMI } \\
\left(\mathrm{kg} / \mathrm{m}^{2}\right)\end{array}$ & $\begin{array}{l}24.7 \\
(3.5)\end{array}$ & $25.3(3.4)$ & $\begin{array}{l}25.4 \\
(3.5)\end{array}$ & 0.018 & $24.6(3.4)$ & 24.9 (3.5) & 25.1(3.5) & 0.047 \\
\hline $\begin{array}{l}\text { Regular } \\
\text { exercise } \\
\text { habits [n } \\
(\%)]\end{array}$ & $\begin{array}{l}327 \\
(56.0)\end{array}$ & 331 (56.9) & $\begin{array}{l}333 \\
(57.0)\end{array}$ & 0.929 & $642(47.9)$ & $\begin{array}{l}617 \\
(46.0)\end{array}$ & $\begin{array}{l}621 \\
(46.3)\end{array}$ & 0.578 \\
\hline $\begin{array}{l}\text { Over } \\
\text { senior } \\
\text { middle } \\
\text { school [n } \\
(\%)]\end{array}$ & $\begin{array}{l}393 \\
(67.3)\end{array}$ & $374(64.3)$ & $\begin{array}{l}346 \\
(59.2)\end{array}$ & 0.015 & $1056(78.7)$ & $\begin{array}{l}985 \\
(73.5)\end{array}$ & $\begin{array}{l}858 \\
(63.9)\end{array}$ & $\begin{array}{l}< \\
0.001\end{array}$ \\
\hline $\begin{array}{l}\text { Current } \\
\text { smokers } \\
\text { [n (\%)] }\end{array}$ & $\begin{array}{l}72 \\
(12.3)\end{array}$ & $92(15.8)$ & $\begin{array}{l}94 \\
(16.1)\end{array}$ & 0.253 & $181(29.1)$ & $\begin{array}{l}198 \\
(31.8)\end{array}$ & $\begin{array}{l}243 \\
(39.1)\end{array}$ & $\begin{array}{l}< \\
0.001\end{array}$ \\
\hline $\begin{array}{l}\text { Current } \\
\text { drinkers [n } \\
(\%)]\end{array}$ & $\begin{array}{l}177 \\
(30.3)\end{array}$ & $171(29.4)$ & $\begin{array}{l}155 \\
(26.5)\end{array}$ & 0.333 & 505 (37.7) & $\begin{array}{l}433 \\
(32.3)\end{array}$ & $\begin{array}{l}475 \\
(35.4)\end{array}$ & 0.014 \\
\hline $\begin{array}{l}\text { Energy } \\
\text { intake } \\
\text { (kcal/day) }\end{array}$ & $\begin{array}{l}2237 \\
(941)\end{array}$ & $2177(748)$ & $\begin{array}{l}2345 \\
(832)\end{array}$ & 0.003 & 2297 (801) & $\begin{array}{l}2311 \\
(1000)\end{array}$ & $\begin{array}{l}2530 \\
(830)\end{array}$ & $\begin{array}{l}< \\
0.001\end{array}$ \\
\hline $\begin{array}{l}\text { Protein } \\
\text { (g/day) }\end{array}$ & $\begin{array}{l}75.7 \\
(24.7)\end{array}$ & $\begin{array}{l}64.5 \\
(25.5)\end{array}$ & $\begin{array}{l}63.8 \\
(24.8)\end{array}$ & $<.001$ & $78.0(50.1)$ & $\begin{array}{l}69.4 \\
(28.6)\end{array}$ & $\begin{array}{l}70.1 \\
(26.2)\end{array}$ & $\begin{array}{l}< \\
0.001\end{array}$ \\
\hline $\begin{array}{l}\text { Fiber } \\
\text { (g/day) }\end{array}$ & $\begin{array}{l}13.6 \\
(8.5)\end{array}$ & $14.3(6.7)$ & $\begin{array}{l}14.7 \\
(6.3)\end{array}$ & 0.061 & $12.4(7.0)$ & $14.4(6.7)$ & $15.3(6.9)$ & $\begin{array}{l}< \\
0.001\end{array}$ \\
\hline
\end{tabular}

Mean \pm Standard Deviation was used for continuous variables.

One-way ANOVA was used for continuous variables; Chi-square tests were used for categorical variables. BMI, body mass index; TG, triglyceride; TCHO, total cholesterol; HDL-c, high-density lipoprotein cholesterol; LDL-c, low-density lipoprotein cholesterol; HbA1c, glycosylated hemoglobin; HPHS, Harbin People health Study; HDNNCDS, the Harbin Cohort Study on Diet, Nutrition and Chronic Noncommunicable Disease 


\begin{tabular}{|c|c|c|c|c|c|c|c|c|}
\hline & HPHS & & & & HDNNCDS & & & \\
\hline $\begin{array}{l}\text { Saturated } \\
\text { fatty acid } \\
\text { (g/day) }\end{array}$ & $\begin{array}{l}18.1 \\
(8.0)\end{array}$ & $14.7(5.9)$ & $\begin{array}{l}12.0 \\
(4.3)\end{array}$ & $\begin{array}{l}< \\
0.001\end{array}$ & $19.3(10.8)$ & $15.9(6.9)$ & $13.5(5.1)$ & $<.001$ \\
\hline $\begin{array}{l}\text { Fasting } \\
\text { glucose } \\
\text { (mmol/L) }\end{array}$ & $\begin{array}{l}4.65 \\
(0.68)\end{array}$ & $\begin{array}{l}4.71 \\
(0.68)\end{array}$ & $\begin{array}{l}4.76 \\
(0.73)\end{array}$ & 0.104 & $4.53(0.64)$ & $\begin{array}{l}4.53 \\
(0.72)\end{array}$ & $\begin{array}{l}4.49 \\
(0.72)\end{array}$ & 0.294 \\
\hline $\begin{array}{l}\text { 2-hour } \\
\text { glucose } \\
\text { (mmol/L) }\end{array}$ & $\begin{array}{l}5.67 \\
(1.64)\end{array}$ & $\begin{array}{l}5.69 \\
(1.68)\end{array}$ & $\begin{array}{l}5.66 \\
(1.69)\end{array}$ & 0.892 & $5.74(1.59)$ & $\begin{array}{l}5.78 \\
(1.62)\end{array}$ & $\begin{array}{l}5.88 \\
(1.70)\end{array}$ & 0.079 \\
\hline $\begin{array}{l}\mathrm{HbA1c} \\
(\%)\end{array}$ & $\begin{array}{l}4.95 \\
(0.51)\end{array}$ & $\begin{array}{l}5.00 \\
(0.56)\end{array}$ & $\begin{array}{l}5.08 \\
(0.61)\end{array}$ & $<.001$ & $5.52(0.87)$ & $\begin{array}{l}5.52 \\
(0.93)\end{array}$ & $\begin{array}{l}5.67 \\
(0.63)\end{array}$ & $\stackrel{<}{0.001}$ \\
\hline $\begin{array}{l}\text { Fasting } \\
\text { insulin } \\
(\mu \mathrm{U} / \mathrm{mL})\end{array}$ & $\begin{array}{l}8.31 \\
(6.94)\end{array}$ & $\begin{array}{l}8.37 \\
(9.15)\end{array}$ & $\begin{array}{l}8.49 \\
(9.91)\end{array}$ & 0.964 & $8.51(6.20)$ & $\begin{array}{l}8.75 \\
(12.4)\end{array}$ & $\begin{array}{l}8.39 \\
(7.89)\end{array}$ & 0.727 \\
\hline $\begin{array}{l}\text { TG } \\
(\mathrm{mmol} / \mathrm{L})\end{array}$ & $\begin{array}{l}1.66 \\
(1.22)\end{array}$ & $\begin{array}{l}1.75 \\
(1.32)\end{array}$ & $\begin{array}{l}1.79 \\
(1.39)\end{array}$ & 0.568 & $1.62(1.57)$ & $\begin{array}{l}1.67 \\
(1.53)\end{array}$ & $\begin{array}{l}1.79 \\
(1.73)\end{array}$ & 0.345 \\
\hline $\begin{array}{l}\mathrm{TCHO} \\
(\mathrm{mmol} / \mathrm{L})\end{array}$ & $\begin{array}{l}4.94 \\
(0.93)\end{array}$ & $\begin{array}{l}4.86 \\
(0.91)\end{array}$ & $\begin{array}{l}4.93 \\
(0.95)\end{array}$ & 0.157 & $5.20(1.03)$ & $\begin{array}{l}5.08 \\
(0.98)\end{array}$ & $\begin{array}{l}5.09 \\
(1.01)\end{array}$ & 0.001 \\
\hline $\begin{array}{l}\mathrm{HDL}-\mathrm{C} \\
(\mathrm{mmol} / \mathrm{L})\end{array}$ & $\begin{array}{l}1.33 \\
(0.32)\end{array}$ & $\begin{array}{l}1.28 \\
(0.32)\end{array}$ & $\begin{array}{l}1.24 \\
(0.32)\end{array}$ & $\begin{array}{l}<.001 \\
0.001\end{array}$ & $1.32(0.33)$ & $\begin{array}{l}1.26 \\
(0.32)\end{array}$ & $\begin{array}{l}1.22 \\
(0.31)\end{array}$ & $\begin{array}{l}< \\
0.001\end{array}$ \\
\hline $\begin{array}{l}\text { LDL-C } \\
(\mathrm{mmol} / \mathrm{L})\end{array}$ & $\begin{array}{l}2.93 \\
(0.98)\end{array}$ & $\begin{array}{l}2.88 \\
(0.97)\end{array}$ & $\begin{array}{l}2.80 \\
(0.96)\end{array}$ & 0.062 & $3.01(0.87)$ & $\begin{array}{l}2.97 \\
(0.82)\end{array}$ & $\begin{array}{l}3.02 \\
(0.88)\end{array}$ & 0.323 \\
\hline \multicolumn{9}{|c|}{ Mean \pm Standard Deviation was used for continuous variables. } \\
\hline \multicolumn{9}{|c|}{$\begin{array}{l}\text { One-way ANOVA was used for continuous variables; Chi-square tests were used for categorical } \\
\text { variables. BMI, body mass index; TG, triglyceride; TCHO, total cholesterol; HDL-c, high-density } \\
\text { lipoprotein cholesterol; LDL-c, low-density lipoprotein cholesterol; HbA1c, glycosylated hemoglobin; } \\
\text { HPHS, Harbin People health Study; HDNNCDS, the Harbin Cohort Study on Diet, Nutrition and Chronic } \\
\text { Noncommunicable Disease }\end{array}$} \\
\hline
\end{tabular}

\section{Association between AACl and incidence of T2DM}

Association between AACl and incidence of T2DM in the two cohorts were presented in the Table 2. In the HPHS, compared with participants in the lowest tertile of AACl, the RRs (95\% Cls) for those in the second and third, were 1.41 (95\% $\mathrm{Cl} 0.86-2.29)$ and 1.76 (1.04-3.02) $\left(P_{\text {for trend }}=0.042\right)$, with adjustment for demographic and nutritional covariates. When the model additionally included biochemical indices, this association become marginally significant. The RRs (95\% Cls) were 1.00 (reference), 1.39 (0.85-2.26) and $1.68(1.01-2.91)\left(P_{\text {for trend }}=0.063\right)$. In the HDNNCDS, compared with participants in the lowest tertile of $\mathrm{AACl}$, the RRs (95\% Cls) for those in the second and third, were $1.35(95 \% \mathrm{Cl} 1.01-1.80)$ and $1.71(1.25-$ 2.33) ( $\left.P_{\text {for trend }}=0.001\right)$, with adjustment for demographic and nutritional covariates. When the model additionally included HOMA-IR and blood lipid profiles, the association between the AACl and risk of T2DM attenuated, but still remained significant. The RRs (95\% Cls) were 1.00 (reference), 1.30 (0.98-1.34) 
and $1.53(1.19-2.23)\left(P_{\text {fortrend }}=0.002\right)$. The two cohorts consistently showed that increased AACI was associated with increased risk of T2DM. In the multivariable regression models (Table 2), the standardised regression coefficients $(\beta)$ of $\mathrm{AACl}$ to HbA1c were $0.084(P=0.003)$ and $0.036(P=0.049)$ in the HPHS and HDNNCDS, respectively, after adjustment for all the above covariates. The two cohorts consistently showed positive association between $\mathrm{AACl}$ and $\mathrm{HbA} 1 \mathrm{c}$.

Table 2

RRs $(95 \% \mathrm{Cl})$ of the incidence of T2DM across tertiles of AACl in the two cohorts.

\begin{tabular}{|c|c|c|c|c|c|}
\hline $\mathrm{AACl}$ & Case/N & Model 1 & Model 2 & Model 3 & Model 4 \\
\hline \multicolumn{6}{|c|}{ HPHS (RR [95\%Cl]) } \\
\hline$<3.32$ & $35 / 584$ & 1 & 1 & 1 & 1 \\
\hline $3.32-3.57$ & $51 / 582$ & $\begin{array}{l}1.51(0.96- \\
2.35)\end{array}$ & $\begin{array}{l}1.38(0.87- \\
2.19)\end{array}$ & $\begin{array}{l}1.41(0.86- \\
2.29)\end{array}$ & $\begin{array}{l}1.39(0.85- \\
2.26)\end{array}$ \\
\hline$>3.57$ & $62 / 584$ & $\begin{array}{l}1.86(1.21- \\
2.87)\end{array}$ & $\begin{array}{l}1.68(1.07- \\
2.62)\end{array}$ & $\begin{array}{l}1.76(1.04- \\
3.02)\end{array}$ & $\begin{array}{l}1.68(1.01- \\
2.91)\end{array}$ \\
\hline$p$ for trend & & 0.018 & 0.023 & 0.042 & 0.063 \\
\hline \multicolumn{6}{|c|}{$\begin{array}{l}\text { HDNNCDS (RR } \\
[95 \% \mathrm{Cl}])\end{array}$} \\
\hline$<3.36$ & $104 / 1341$ & 1 & 1 & 1 & 1 \\
\hline $3.36-3.53$ & $130 / 1341$ & $\begin{array}{l}1.28(0.98- \\
1.67)\end{array}$ & $\begin{array}{l}1.20(0.91- \\
1.58)\end{array}$ & $\begin{array}{l}1.35(1.01- \\
1.80)\end{array}$ & $\begin{array}{l}1.30(0.98- \\
1.34)\end{array}$ \\
\hline$>3.53$ & $151 / 1342$ & $\begin{array}{l}1.51(1.16- \\
1.96)\end{array}$ & $\begin{array}{l}1.35(1.04- \\
1.77)\end{array}$ & $\begin{array}{l}1.71(1.25- \\
2.33)\end{array}$ & $\begin{array}{l}1.63(1.19- \\
2.23)\end{array}$ \\
\hline$p$ for trend & & 0.002 & 0.030 & 0.001 & 0.002 \\
\hline \multicolumn{6}{|c|}{ HbA1c( $\beta$ [p-value] $)$} \\
\hline HPHS & $88 / 1750$ & $\begin{array}{l}0.083(< \\
0.001)\end{array}$ & $0.065(0.005)$ & $0.084(0.003)$ & $0.084(0.003)$ \\
\hline HDNNCDS & $255 / 4024$ & $\begin{array}{l}0.053(< \\
0.001)\end{array}$ & $0.044(0.006)$ & $0.037(0.040)$ & $0.036(0.049)$ \\
\hline
\end{tabular}

Data are RRs $(95 \% \mathrm{Cl})$ or $\beta$ ( $P$-value)

Model 1 was crude model

Model 2 was further adjusted by demographic covariates including age, gender, BMI, education, alcohol consumption rate, smoking rate and regular exercise habits;

Model 3 was further adjusted by nutritional covariates including dietary energy intake, protein intake, fiber, saturated fatty acid and overall diet quality

Model 4 was further adjusted by biochemical indices including total cholesterol, triglyceride, highdensity lipoprotein cholesterol, low-density lipoprotein cholesterol and HOMA2-IR; 


\section{Association of AACl with serum AAs profiles}

Associations of $\mathrm{AACl}$ with serum AAs profiles in the two cohorts were presented in the Table 3 . In the $\mathrm{HPHS}, \mathrm{AACl}$ was positively associated with levels of serum glutamine, valine, isoleucine, glutamic acid and phenylalanine, and it was negatively associated with levels of glycine, proline and histidine (all the $P$ $<0.01)$. In the HDNNCDS, AACI was positively associated with leucine, valine, isoleucine, serine, alanine, phenylalanine and tryptophan, and it was negatively associated with levels of glycine and histidine (all the $P<0.01)$. The AACl was consistently associated with six of eighteen serum AAs including valine, isoleucine, glycine, glutamic acid, phenylalanine and histidine in the two cohorts. 
Table 3

The associations between $\mathrm{AACl}$ and serum amino acids profiles

\begin{tabular}{|c|c|c|c|c|c|c|}
\hline & \multicolumn{3}{|l|}{ HPHS } & \multicolumn{3}{|c|}{ HDNNCDS } \\
\hline & Model 1 & Model 2 & Model 3 & Model 1 & Model 2 & Model 3 \\
\hline Threonine & 0.035 & 0.032 & 0.053 & 0.018 & 0.025 & 0.029 \\
\hline Glutamine & $0.116^{\star *}$ & $0.116^{\star \star}$ & $0.119^{* \star}$ & 0.006 & 0.007 & 0.011 \\
\hline Leucine & 0.025 & 0.003 & 0.012 & $0.107^{\star \star}$ & $0.086^{* *}$ & $0.084^{\star \star}$ \\
\hline Arginine & -0.016 & -0.013 & 0.013 & 0.024 & $0.041^{* *}$ & $0.043^{* *}$ \\
\hline Valine & $0.134^{\star \star}$ & $0.125^{\star *}$ & $0.148^{\star *}$ & $0.042^{\star *}$ & $0.045^{\star *}$ & $0.042^{\star *}$ \\
\hline Isoleucine & $0.146^{\star \star}$ & $0.130^{\star \star}$ & $0.147^{\star \star}$ & $0.117^{\star \star}$ & $0.096^{\star \star}$ & $0.088^{\star \star}$ \\
\hline Serine & 0.033 & 0.042 & 0.051 & 0.011 & $0.038^{*}$ & $0.045^{\star \star}$ \\
\hline Methionine & -0.013 & -0.019 & -0.005 & 0.031 & 0.010 & 0.007 \\
\hline Glycine & $-0.074^{*}$ & $-0.070^{*}$ & $-0.080^{*}$ & $-0.069^{* *}$ & $-0.055^{* *}$ & $-0.050^{* *}$ \\
\hline Alanine & 0.009 & 0.007 & 0.012 & $0.079^{\star \star}$ & $0.075^{\star \star}$ & $0.075^{\star \star}$ \\
\hline Lysine & 0.006 & -0.007 & 0.005 & 0.011 & -0.003 & -0.006 \\
\hline Glutamic acid & $0.126^{\star \star}$ & $0.120^{\star \star}$ & $0.115^{\star *}$ & $0.097^{\star *}$ & $0.089^{* *}$ & $0.083^{* *}$ \\
\hline Aspartic acid & -0.009 & -0.011 & -0.008 & 0.025 & 0.027 & 0.033 \\
\hline Tyrosine & 0.005 & 0.005 & 0.033 & 0.014 & 0.023 & 0.018 \\
\hline Phenylalanine & $0.070^{\star \star}$ & $0.090^{\star \star}$ & $0.090^{* *}$ & $0.100^{\star \star}$ & $0.115^{\star \star}$ & $0.116^{\star *}$ \\
\hline Tryptophan & -0.016 & -0.021 & -0.017 & $0.063^{\star \star}$ & $0.074^{\star \star}$ & $0.073^{\star \star}$ \\
\hline Proline & $-0.078^{*}$ & $-0.097^{\star \star}$ & $-0.098^{* \star}$ & 0.023 & 0.019 & 0.018 \\
\hline
\end{tabular}

Data are standard coefficients in the multivariate regression analysis.

Model 1 no adjustment;

Model 2 was adjusted by age, gender, body mass index, alcohol, smoke, regular exercise habits, education level and family history of diabetes;

Model 3 was adjusted by all variables in model 2 and total calorie intake, dietary protein intakes, dietary fiber;

$\star P<0.05$ for the coefficients being different from 0 ; $* \star P<0.01$ for the coefficients being different from 0 . 
HPHS

Histidine
$-0.142^{* *}$

\section{HDNNCDS}

Data are standard coefficients in the multivariate regression analysis.

Model 1 no adjustment;

Model 2 was adjusted by age, gender, body mass index, alcohol, smoke, regular exercise habits, education level and family history of diabetes;

Model 3 was adjusted by all variables in model 2 and total calorie intake, dietary protein intakes, dietary fiber;

$\star P<0.05$ for the coefficients being different from 0 ; $* * P<0.01$ for the coefficients being different from 0 .

\section{Association of serum AAs profiles with T2DM}

As six serum AAs were consistently observed to be associated with $\mathrm{AACl}$ in the two cohorts, the associations of these serum AAs and risk of T2DM were further analysed in the two cohorts (Supplementary Table 2). In the HPHS, after adjustment for covariates, valine, isoleucine, glutamic acid and histidine were associated with T2DM, with the RRs $(95 \% \mathrm{Cl})$ from the bottom to the top quartiles being 1 (reference), 1.71(0.79-3.71), 2.28 (1.08-4.79), 2.55 (1.23-5.28) for valine; 1 (reference), 1.37 (0.762.49), 1.82(1.02-3.24), 2.22 (1.26-3.93) for isoleucine; 1 (reference), 1.46 (0.79-2.69), 2.34(1.31-4.17), 2.46 (1.38-4.37) for glutamic acid; and 1 (reference), 0.76 (0.46-1.25), 0.58 (0.34-0.99), 0.36 (0.20$0.67)$ for histidine. In the HDNNCDS, valine, glycine, glutamic acid, phenylalanine and histidine were associated with T2DM, with the RRs $(95 \% \mathrm{Cl})$ from the bottom to the top quartiles being 1 (reference), $0.81(0.57-1.15), 1.07(0.76-1.50), 2.36(1.73-3.21)$ for valine; 1 (reference), 0.89(0.66-1.18), 0.59(0.43$0.81), 0.56(0.40-0.78)$ for glycine; 1 (reference), $0.81(0.56-1.17), 1.35(0.98-1.86), 1.75(1.26-2.41)$ for glutamic acid; 1 (reference), $0.83(0.60-1.16), 1.24(0.90-1.70), 1.54(1.14-2.08)$ for phenylalanine and 1 (reference), $0.85(0.61-1.19), 0.63(0.42-1.04), 0.43(0.28-0.65)$ for histidine. Valine, glutamic acid and histidine were consistently associated with T2DM in the two cohorts.

\section{Mediation analysis}

Figure 2 shows mediation effects of the above three serum AAs on the association between the AACl and T2DM in the two cohorts. The total effect of the AACl on risk of T2DM measured as standardized regression coefficient $\left(\beta_{\text {tot }}=0.512 ; P<0.001\right.$ in the HPHS; $\beta_{\text {tot }}=0.271 ; P<0.001$ in the HDNNCDS) was estimated without the three serum AAs in the model with adjustment for covariates. The $\beta_{1}$ to $\beta_{6}$ were used to calculate the overall indirect effect for BCAAs, AAAs and histidine respectively. The percentages of the total effect mediated by valine, glutamic acid and histidine were estimated at $10.5 \%, 13.3 \%$ and $9.6 \%$ in the HPHS, and $11.1 \%, 17.7 \%$ and $25.8 \%$ in the HDNNCDS.

\section{Discussion}


To our knowledge, this study is the first to address the link between dietary AAs composition and its serum profiles in relation to incidence of T2DM. To evaluate the overall quality of dietary AAs compositions, AACl was developed in this study by assessing the extent to which overall dietary AAs compositions adherence to the HRAAP. In the two prospective cohorts, the AACl was consistently and positively associated with six serum AAs and the incidence of T2DM. Among the six serum AAs, serum valine, glutamic acid and histidine consistently and partially mediated the association between the AACl and T2DM in the two cohorts.

In this study, using two prospective cohorts, a positive association between the AACl and incidence of T2DM was consistently observed, suggesting that participants with low quality of overall dietary essential AAs composition may have a higher risk of T2DM. Based on the concept of the HRAAP, biological value of individual AAs can be influenced by overall dietary AAs compositions, resulting in different absorbed-, utilized-and metabolic-rates of dietary $\mathrm{AAs}(8-11)$. Inadequate dietary AAs compositions therefore may play important roles in the development of T2DM. This study also demonstrated that when additionally adjusted for other known dietary risk factors for T2DM including intake of total protein (29), fiber (30), saturated fat (31), and overall diet quality (32), the relationship between the AACl and incidence of T2DM was still significant, further indicating that inadequate dietary AAs composition was likely an important dietary factor for residual risk of T2DM. These findings are supported by previous study showing that risk of pre-diabetes varied with different dietary AAs patterns (33), and they are also supported by cell and animal studies with the fact that feeding with mixture of AAs rather than a single AA alone could promote development of insulin-resistance and $\beta$-cell dysfunction in rodents $(34,35)$. Taken together, these accumulating evidences suggest that dietary AAs composition is likely an important risk factor in prevention and management of T2DM.

Previous studies have reported that individual dietary AAs intake cannot commonly be reflected in serum AAs levels $(3,12,13)$, which makes current study of this issue lack compelling evidence for understanding the relationship between dietary AAs and T2DM. To fill this gap, this study further examined the association between the AACl and serum profiles of AAs in the two cohorts. The AACl was associated with eight serum AAs in the HPHS, and it was associated with nine serum AAs in the HDNNCDS. Although the difference of sample size and heterogeneity between the two cohorts are possible reasons for these discrepancy results, the serum valine, isoleucine, glycine, glutamic acid, phenylalanine and histidine were consistently observed to be associated with the AACl in the two cohorts, demonstrating that dietary AAs composition would influence the absorbed-, utilized- and metabolic-rates of AAs, which can be reflected in the serum AAs profiles, supporting the concept of the HRAAP for the impact of dietary AAs composition on their serum profiles. Studies regarding this issue were relative scarce, but a recent study has reported that it is overall dietary pattern rather than dietary BCAA was associated with serum BCAA, which partially support the observations in this study (36).

To further clarified whether and how the association between the AACl and incidence of T2DM mediated by serum AAs profiles for understanding the impact of dietary AAs composition on their serum profiles in relation to subsequent T2DM, mediation analyses were performed in the two cohorts. Although the AACI 
was consistently associated with six serum AAs in the two cohorts, only serum valine, glutamic acid and histidine consistently and partially mediated this association in the two cohorts with total mediation effects of $33.4 \%$ and $54.6 \%$, respectively, indicating that the association between inappropriate dietary AAs composition and increased risk of T2DM may be largely mediated by increasing serum valine and glutamic acid, and by decreasing serum histidine levels. Serum valine, as one of the BCAAs, has been consistently identified to be an important metabolite associated with insulin-resistance in previous epidemiologic studies $(15-19,37)$, probably through inhibition of insulin receptor substrate-1, and a recent study has reported that increased serum BCAAs probably produce more catabolic intermediates including propionyl CoA and succinyl CoA, resulting in accumulation of incompletely oxidized fatty acids and glucose (38). Moreover, BCAAs can produce glutamic acids, catalyzing by branched-chain aminotransferase, and the glutamic acids has been reported to be associated with insulin resistance in the Framingham offspring study (39). The potential protective effect of histidine on glucose/insulin homeostasis has been documented in previous research, probably by suppressing inflammatory factors and hepatic glucose production through central insulin action (40). Based on the findings in this study and these above mechanisms, this study therefore speculated that an inappropriate dietary AAs composition may cause varied absorbed-, utilized-and metabolic-rate of AAs, showing disordered plasma AAs profiles, and the dysregulated valine, glutamic acid and histidine may induce insulin resistance and subsequent diabetes.

Previous studies regarding this issue have frequently focused on the association between individual AA and T2DM, few studies have considered the overall quality of dietary AAs compositions. This study demonstrated that inadequate dietary AAs composition was associated with increased incidence of T2DM, and the association between the AACl and serum AAs profiles and the potential mediation effects further strength our findings, which would improve our understanding of the pathobiology and mechanisms of T2DM, and facilitate selection of potential therapeutic and intervention strategies for T2DM. Moreover, the findings of this study also emphasized that future study regarding dietary AAs and T2DM should consider dietary AAs as a whole rather than isolating individual AAs from diet in prevention and management of T2DM.

The strength of our study is that it included two prospective cohorts with relatively large OGTT sample of nutritional and metabolic analyses in this issue. Further, this study established the AACl based on the concept of the HRAAP for evaluating the overall quality of dietary AAs composition, demonstrated and emphasized the importance of dietary AAs composition. Third, the observed association between the AACI and T2DM was robust because it was observed in the two independent cohorts and it persisted after adjustment for a wide range of available confounding factors. However, we also recognize that our study has certain limitations. First, the study was observational in nature, and we cannot rule out the influence of unmeasured confounding factors. Besides, no amount of adjustment can deal completely with confounding in an observational context. Second, this study only included Asian subjects, which is likely to limit the generalizability of our findings to other ethnic populations. However, given the roles of HRAAP, and the association between serum AAs and T2DM have been shown to be generally consistent across different ethnics. We would therefore expect that our observations would hold across other populations. 


\section{Conclusions}

In conclusion, this study demonstrated that dietary AAs composition was association with incidence of T2DM, which was likely responsible for the residual risk of classic known dietary factors for T2DM.

Further, dietary AAs composition was associated with serum profiles of AAs, and serum valine, glutamic acid and histidine partially mediated the association between the inadequate dietary AAs composition and increased risk of T2DM. These findings may have important implications for the possible therapeutic and intervention strategies of T2DM.

\section{Abbreviations}

1. BMI, body mass index;

2. AAs, amino acids;

3. BCAAs, branched chain amino acids

4. $\mathrm{AACl}$, amino acid compositions index;

5. HDNNCDS, the Harbin Cohort Study on Diet, Nutrition and Chronic Noncommunicable Disease;

6. HPHS, the Harbin People Health study;

7. TG, triacylglycerol;

8. HDL-C, high density lipoprotein cholesterol;

9. TC, total cholesterol;

10. LDL-C, low density lipoprotein cholesterol;

11. HOMA-IR, Homeostasis assessment model for insulin resistance

12. HRAAP, human requirement amino acids pattern

\section{Declarations}

\section{Ethics approval and consent to participate}

The two cohort studies were approved by the ethics committee of Harbin Medical University. The investigations were conducted in accordance with the Declaration of Helsinki, and written informed consent was provided by all participants.

\section{Consent for publication}

All authors have read and approved the final version of the manuscript.

\section{Availability of data and materials}


The authors confirm that the data supporting the findings of this study are available within the article [and/or] its supplementary materials.

\section{Competing interests}

All authors declare that there are no conflicts of interest.

\section{Funding}

This research was supported funds from National Key R\&D Program of China (2017YFC1307401 to Changhao Sun) and Open Research Fund for Top Disciplines of Public Health and Prevent Medicine at Ningxia Medical University (30181302 to Ying Li).

\section{Authors contribution}

WD, TH and YZ conceived the idea. WD drafted the manuscript. TH and RS conducted statistical analyses. $Y Z, H W, H S$ and ZT did the amino acid measurements. All authors critically assessed and reviewed the paper. Changhao Sun and Ying Li take responsibility for the contents of the article.

\section{Acknowledgements}

We thank all participants in this study for their continued cooperation and participation.

\section{References}

1. Bloomgarden Z. Diabetes and branched-chain amino acids: What is the link? J Diabetes. 2018;10:350-2.

2. Gar C, Rottenkolber M, Prehn C, Adamski J, Seissler J, Lechner A. Serum and plasma amino acids as markers of prediabetes, insulin resistance, and incident diabetes. Crit Rev Clin Lab Sci. 2018;55:2132.

3. Jennings A, MacGregor A, Pallister T, Spector T, Cassidy A. Associations between branched chain amino acid intake and biomarkers of adiposity and cardiometabolic health independent of genetic factors: A twin study. Int J Cardiol. 2016;223:992-8.

4. Nagata C, Nakamura K, Wada K, Tsuji M, Tamai Y, Kawachi T. Branched-chain amino acid intake and the risk of diabetes in a Japanese community: the Takayama study. Am J Epidemiol. 2013;178:1226-32.

5. van Loon LJ, Kruijshoop M, Menheere PP, Wagenmakers AJ, Saris WH, Keizer HA. Amino acid ingestion strongly enhances insulin secretion in patients with long-term type 2 diabetes. Diabetes Care. 2003;26:625-30. 
6. Argyrakopoulou G, Kontrafouri P, Eleftheriadou I, et al. The Effect of the Oral Administration of Leucine on Endothelial Function, Glucose and Insulin Concentrations in Healthy Subjects. Exp Clin Endocrinol Diabetes 2018.

7. Leenders $M$, Verdijk LB, van der Hoeven L, et al. Prolonged leucine supplementation does not augment muscle mass or affect glycemic control in elderly type 2 diabetic men. J Nutr. 2011;141:1070-6.

8. Moore DR, Soeters PB. The Biological Value of Protein. Nestle Nutr Inst Workshop Ser. 2015;82:3951.

9. Albanese AA, Irby V. Observations on the Biological Value of a Mixture of Essential Amino Acids. Science. 1943;98:286-8.

10. Acevedo-Pacheco L, Serna-Saldivar So. In vivo protein quality of selected cereal-based staple foods enriched with soybean proteins. Food Nutr Res. 2016;60:31382.

11. Jonker R, Engelen MP, Deutz NE. Role of specific dietary amino acids in clinical conditions. Br J Nutr. 2012;108(Suppl 2):139-48.

12. McCormack SE, Shaham O, McCarthy MA, et al. Circulating branched-chain amino acid concentrations are associated with obesity and future insulin resistance in children and adolescents. Pediatr Obes. 2013;8:52-61.

13. Schmidt JA, Rinaldi S, Scalbert A, et al. Plasma concentrations and intakes of amino acids in male meat-eaters, fish-eaters, vegetarians and vegans: a cross-sectional analysis in the EPIC-Oxford cohort. Eur J Clin Nutr. 2016;70:306-12.

14. Zheng Y, Li Y, Qi Q, et al. Cumulative consumption of branched-chain amino acids and incidence of type 2 diabetes. Int J Epidemiol. 2016;45:1482-92.

15. Lee CC, Watkins SM, Lorenzo C, et al. Branched-Chain Amino Acids and Insulin Metabolism: The Insulin Resistance Atherosclerosis Study (IRAS). Diabetes Care. 2016;39:582-8.

16. Wurtz $\mathrm{P}$, Tiainen M, Makinen VP, et al. Circulating metabolite predictors of glycemia in middle-aged men and women. Diabetes Care. 2012;35:1749-56.

17. Wang TJ, Larson MG, Vasan RS, et al. Metabolite profiles and the risk of developing diabetes. Nat Med. 2011;17:448-53.

18. Tai ES, Tan ML, Stevens RD, et al. Insulin resistance is associated with a metabolic profile of altered protein metabolism in Chinese and Asian-Indian men. Diabetologia. 2010;53:757-67.

19. Guasch-Ferre M, Hruby A, Toledo E, et al. Metabolomics in Prediabetes and Diabetes: A Systematic Review and Meta-analysis. Diabetes Care. 2016;39:833-46.

20. Cogate PG, Natali AJ, de Oliveira A, Alfenas RC, Hermsdorff HH. Consumption of Branched-Chain Amino Acids Is Inversely Associated with Central Obesity and Cardiometabolic Features in a Population of Brazilian Middle-Aged Men: Potential Role of Leucine Intake. J Nutr Health Aging. 2015;19:771-7.

21. Isanejad $M$, LaCroix $A Z$, Thomson $C A$, et al. Branched-chain amino acid, meat intake and risk of type 2 diabetes in the Women's Health Initiative. Br J Nutr. 2017;117:1523-30. 
22. Joint WHOFAOUNUEC. Protein and amino acid requirements in human nutrition. World Health Organ Tech Rep Ser 2007:1-265, back cover.

23. Na L, Wu X, Feng R, et al. The Harbin Cohort Study on Diet, Nutrition and Chronic Non-communicable Diseases: study design and baseline characteristics. PLoS One. 2015;10:e0122598.

24. Du S, Wu X, Han T, Duan W, Liu L, Qi J, Niu Y, Na L, Sun C. Dietary manganese and type 2 diabetes mellitus: two prospective cohort studies in China. Diabetologia. 2018;61:1985-95.

25. Yang Y, Wang G, Pan X. China Food Composition Tables. China: Beijing University Medical Press; 2009.

26. Wang DD, Leung CW, Li Y, Ding EL, Chiuve SE, Hu FB, Willett WC. Trends in dietary quality among adults in the United States, 1999 through 2010. JAMA Intern Med. 2014;174:1587-95.

27. Liu L, Feng R, Guo F, Li Y, Jiao J, Sun C. Targeted metabolomic analysis reveals the association between the postprandial change in palmitic acid, branched-chain amino acids and insulin resistance in young obese subjects. Diabetes Res Clin Pract. 2015;108:84-93.

28. Rosseel Y. lavaan: An R Package for Structural Equation Modeling. J Stat Softw 2012;48.

29. van Nielen M, Feskens EJ, Mensink M, et al. Dietary protein intake and incidence of type 2 diabetes in Europe: the EPIC-InterAct Case-Cohort Study. Diabetes Care. 2014;37:1854-62.

30. InterAct C. Dietary fibre and incidence of type 2 diabetes in eight European countries: the EPIC-InterAct Study and a meta-analysis of prospective studies. Diabetologia. 2015;58:1394-408.

31. Riserus U, Willett WC, Hu FB. Dietary fats and prevention of type 2 diabetes. Prog Lipid Res. 2009;48:44-51.

32. Ley SH, Pan A, Li Y, et al. Changes in Overall Diet Quality and Subsequent Type 2 Diabetes Risk: Three U.S. Prospective Cohorts. Diabetes Care. 2016;39:2011-8.

33. Mirmiran P, Bahadoran Z, Esfandyari S, Azizi F. Dietary Protein and Amino Acid Profiles in Relation to Risk of Dysglycemia: Findings from a Prospective Population-Based Study. Nutrients 2017;9.

34. Newgard CB, An J, Bain JR, et al. A branched-chain amino acid-related metabolic signature that differentiates obese and lean humans and contributes to insulin resistance. Cell Metab. 2009;9:31126.

35. Zhang Y, Guo K, LeBlanc RE, Loh D, Schwartz GJ, Yu YH. Increasing dietary leucine intake reduces diet-induced obesity and improves glucose and cholesterol metabolism in mice via multimechanisms. Diabetes. 2007;56:1647-54.

36. Merz B, Frommherz L, Rist MJ, Kulling SE, Bub A, Watzl B. Dietary Pattern and Plasma BCAAVariations in Healthy Men and Women-Results from the KarMeN Study. Nutrients 2018;10.

37. Wang TJ, Larson MG, Vasan RS, Cheng S, Rhee EP, McCabe E, Lewis GD, Fox CS, Jacques PF, Fernandez C, et al. Metabolite profiles and the risk of developing diabetes. Nat Med. 2011;17:448-53.

38. Newgard CB. Interplay between lipids and branched-chain amino acids in development of insulin resistance. Cell Metab. 2012;15:606-14. 
39. Cheng S, Rhee EP, Larson MG, Lewis GD, McCabe EL, Shen D, Palma MJ, Roberts LD, Dejam A, Souza AL, et al. Metabolite profiling identifies pathways associated with metabolic risk in humans. Circulation. 2012;125:2222-31.

40. Kimura K, Nakamura Y, Inaba Y, et al. Histidine augments the suppression of hepatic glucose production by central insulin action. Diabetes. 2013;62:2266-77.

\section{Figures}
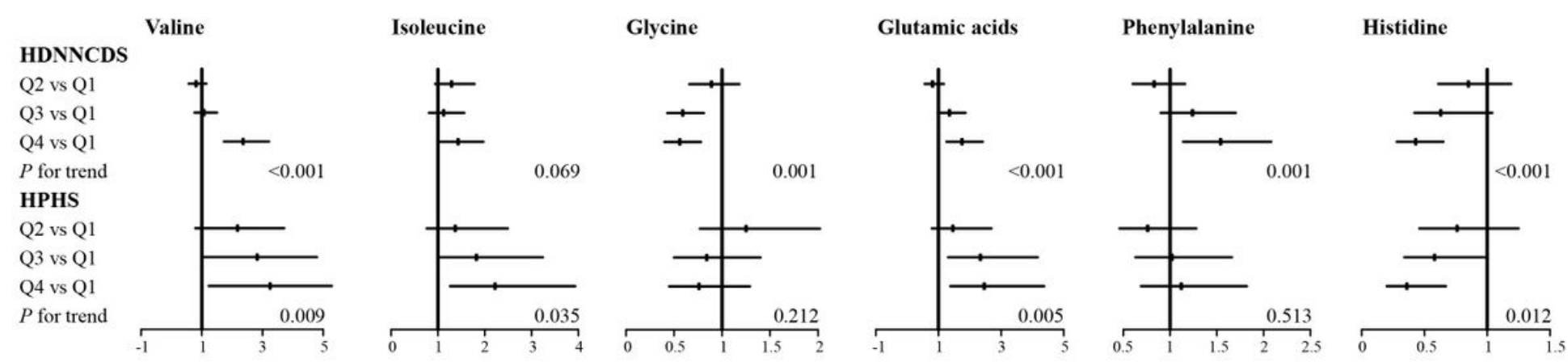

Risk Ratio

\section{Figure 1}

Associations of serum valine, glutamic acid and histidine with incidence of T2DM Data are RR and its $95 \% \mathrm{Cl}$ with adjustment for age, gender, $\mathrm{BMI}$, education, alcohol consumption rate, smoking rate, regular exercise habits, dietary energy intake, protein intake, fiber, saturated fatty acid, overall diet quality, AACl, total cholesterol, triglyceride, high-density lipoprotein cholesterol, low-density lipoprotein cholesterol and HOMA2-IR; HPHS, Harbin People Health Study; HDNNCDS, the Harbin Cohort Study on Diet, Nutrition and Chronic Noncommunicable Disease. 
A

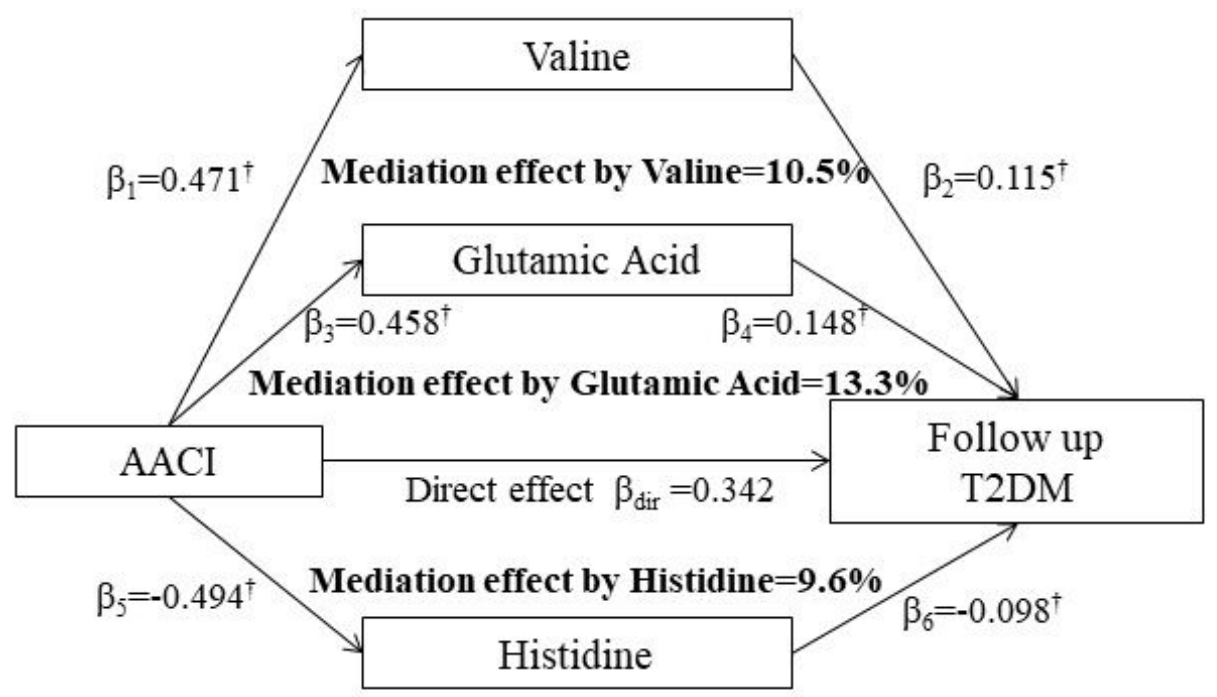

B

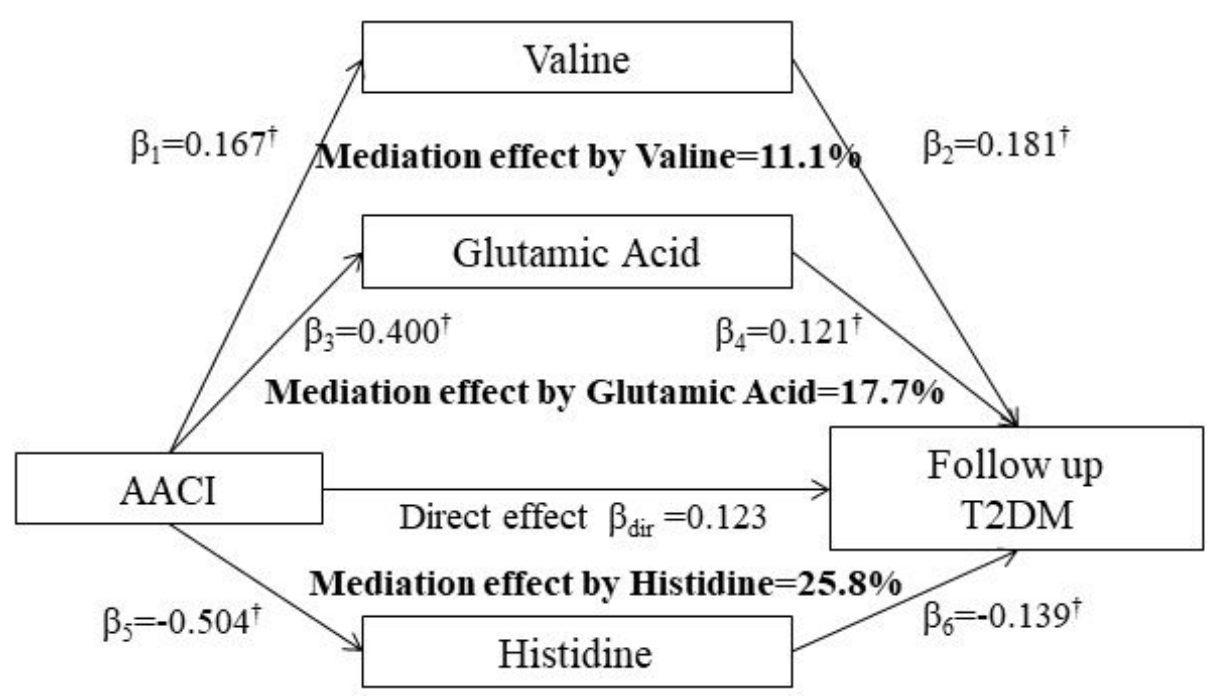

Figure 2

Mediation effects of serum valine, glutamic acid and histidine on the association between the AACl and incidence of type 2 diabetes in the HPHS and HDNNCDS. AACl, dietary amino acids composition index; $†$ $\mathrm{P}<0.05$ for the coefficients being different from 0. HPHS, Harbin People health Study; HDNNCDS, the Harbin Cohort Study on Diet, Nutrition and Chronic Noncommunicable Disease

\section{Supplementary Files}

This is a list of supplementary files associated with this preprint. Click to download.

- Additionalfile1.docx 